Article

\title{
Self-Healing Coatings Based on Linseed-Oil-Loaded Microcapsules for Protection of Cementitious Materials
}

\author{
Dong-Min Kim ${ }^{\circledR}$, In-Ho Song, Ju-Young Choi ${ }^{\circledR}$, Seung-Won Jin, Kyeong-Nam Nam \\ and Chan-Moon Chung * \\ Department of Chemistry, Yonsei University, Wonju, Gangwon-do 26493, Korea; \\ dmkimr@yonsei.ac.kr (D.-M.K.); segunda@nate.com (I.-H.S.); cjy0510@yonsei.ac.kr (J.-Y.C.); \\ jinsw0906@yonsei.ac.kr (S.-W.J.); nkn001@naver.com (K.-N.N.) \\ * Correspondence: cmchung@yonsei.ac.kr; Tel.: +82-33-760-2266
}

Received: 1 October 2018; Accepted: 12 November 2018; Published: 15 November 2018

check for updates

\begin{abstract}
Linseed oil undergoes an oxidative drying reaction upon exposure to air, resulting in a soft film. The reaction conversion after $48 \mathrm{~h}$ reached $88 \%$ and $59 \%$ when it reacted at room temperature and $-20{ }^{\circ} \mathrm{C}$, respectively. Linseed-oil-loaded microcapsules were prepared using a urea-formaldehyde polymer as the shell wall material. The microcapsules were integrated into a commercially available protective coating formulation to prepare self-healing coating formulations with different capsule loadings. The coating formulations were applied on mortar specimens to prepare self-healing coatings. The effect of capsule loading on adhesion strength of the self-healing coating was studied. The self-healing function of the coating was investigated by SEM, a water sorptivity test and an accelerated carbonation test. Successful self-healing was demonstrated for both scratch and crack damage in the coatings. Low-temperature self-healing was demonstrated with a saline solution sorptivity test conducted at $-20^{\circ} \mathrm{C}$. The linseed-oil-based microcapsule-type self-healing coating system is a promising candidate as a protective coating for cementitious materials.
\end{abstract}

Keywords: self-healing; protective coating; microcapsule; linseed oil; cementitious materials

\section{Introduction}

A protective coating applied to the surface of a substrate material protects it from various environmental deterioration factors such as water, chloride ions, carbon dioxide and other corrosive substances. If the coating is damaged by cracking or scratching, however, those corrosive substances can penetrate through the damaged area. This results in deterioration of the substrate material, leading to significant reduction of its serviceability. Recently, self-healing protective coatings, which can automatically heal the damage that occurs in them, have been extensively studied to extend material lifetime, reduce maintenance cost and enhance public safety [1-3]. Self-healing is especially important for invisible microdamage that occurs in protective coatings.

Self-healing coatings can be classified into two groups: intrinsic and extrinsic [4]. Intrinsic-type coatings possess a latent self-healing functionality, so they can heal by the coating matrixes themselves. In extrinsic-type self-healing coatings, a healing agent is microencapsulated and embedded into the coating matrix in advance. When the microcapsules are ruptured by damage, a healing agent is released and fills the damaged region, which then undergoes a healing reaction. A microcapsule-based coating system has a major advantage in that it can heal a larger damage volume compared to an intrinsic self-healing system without microcapsules [5].

Linseed oil (Figure S1 in Supplementary Materials) is a drying oil, which means that it hardens to a solid film after a period of exposure to air: linseed oil undergoes a crosslinking reaction in the presence 
of atmospheric oxygen [6]. For microcapsule-type self-healing coatings, linseed oil has attracted much attention as a healing agent due to its good film-forming ability, environmentally friendly nature and low cost. So far, most self-healing protective coatings based on linseed-oil-loaded microcapsules have been developed for metal protection [7-22]. As far as we know, there has been no report on linseed-oil-based microcapsule-type self-healing coatings for application to cementitious materials.

Cementitious materials are the most widely used building materials all over the world. However, deterioration is inevitable even since the very beginning of the service life, then maintenance and repair work, which are often labor- and capital-intensive, would be followed [23]. In the present study, a linseed oil healing agent was applied to a microcapsule-type self-healing coating system for application to cementitious materials. The adhesion strength of the self-healing coating on the mortar was measured and water sorptivity and accelerated carbonation tests were conducted to evaluate the self-healing performance of the coating. In particular, the low-temperature self-healing capability of the coating system was investigated because most protective coatings for cementitious materials can be exposed to a low-temperature environment in winter. In addition, self-healing of crack as well as scratch was investigated in this work, while most research on the microcapsule-type self-healing coatings has focused on self-healing of scratch damage [1-3].

\section{Materials and Methods}

\subsection{Materials}

Urea, formaldehyde solution (37 wt \%), poly(ethylene-alt-maleic anhydride) (EMA), resorcinol, 1-octanol and ammonium chloride were purchased from Sigma-Aldrich Korea (Seoul, Korea) and used in the microencapsulation process. Linseed oil was purchased from Shinhan Art Materials (Seoul, Korea). Acrylic undercoating and top-coating formulations (Wrapping Coat ${ }^{\circledR}$ ) were kindly donated from Samjoong Construction Chemicals Co. (Pocheon, Korea) and used as coating materials. Mortar specimens were prepared with a cement:sand:water mass ratio of 2:6:1 according to the KSF2476 standard method. The paste was mixed and poured in a mold $\left(40 \times 40 \times 120 \mathrm{~mm}^{3}, 70 \times 70 \times 20 \mathrm{~mm}^{3}\right.$, or $100 \times 100 \times 100 \mathrm{~mm}^{3}$ ). The mortar paste was first cured in a mold for $48 \mathrm{~h}$ at room temperature. Each mortar was further cured for 5 days in water and then finally cured for 7 days under ambient conditions.

\subsection{Instruments}

Infrared (IR) spectra were recorded on a Fourier transform infrared (FT-IR) spectrophotometer (Spectrum One B, Perkin Elmer Co., Waltham, MA, USA). A low-temperature chamber (LTC-27, Lab house, Pocheon, Korea) was used to study the reaction of linseed oil and to evaluate self-healing performance at $-20{ }^{\circ} \mathrm{C}$. A mechanical stirrer (NZ-1000, Eyela, Tokyo, Japan) equipped with a propeller-type impeller was used for microencapsulation. A microscope (BX-51, Olympus, Tokyo, Japan) was used to produce images of microcapsules. Microcapsule size was analyzed using a CCD camera (HK6U3Cool, Koptic, Seoul, Korea) in the microscope and image analysis software (HKBasic, Koptic, X64, 3.7.7780). Mean diameter and size distribution were determined from data set of at least 1000 measurements. An electronic balance (ML303, Mettler Toledo, OH, USA) was used to weigh materials used in this work. An infrared thermometer (35639-20, Oakion, Vernon Hills, IL, USA) was used to measure the temperature of coating samples. Pull-off adhesion tests were conducted with a pull-off adhesion tester (SFM-10E, United Testing System, Fullerton, CA, USA). Accelerated carbonation tests were conducted with a carbonation tester (Geesco, YongIn, Korea). A field emission scanning electron microscope (FE-SEM, SU-70, Hitachi, Tokyo, Japan) was used to examine the morphology of the microcapsules and the scratched area of the coatings. Coating samples on silicon wafers were used for the SEM study. Microcracks were generated in coated mortars using three-point bending mode in a universal testing machine (UTM) (QC-505M1, Cometech Testing Machine, Taichung, Taiwan). The UTM was set to stop when the load dropped below $99 \%$ of maximum strength. Scratch 
and crack widths were measured using a portable digital microscope (HB008, HiMax Tech., Seoul, Korea).

\subsection{Reaction Conversion Measurement}

Linseed oil was applied to a petri dish and allowed to react for 7 days at room temperature $\left(23-27^{\circ} \mathrm{C}\right)$ or at $-20^{\circ} \mathrm{C}$. Samples were collected periodically and analyzed by FT-IR spectroscopy $[6,10]$. The degree of conversion of $\mathrm{C}=\mathrm{C}$ groups of linseed oil was analyzed by an IR band-ratio method. The absorbance of the $\mathrm{C}-\mathrm{H}$ stretch band $(=\mathrm{CH}-)$ at $3011 \mathrm{~cm}^{-1}$ was divided by that of a reference $\mathrm{C}-\mathrm{H}$ stretch band $\left(-\mathrm{CH}_{2}-\right)$ at $2928 \mathrm{~cm}^{-1}$. The $2928 \mathrm{~cm}^{-1}$ absorption band was used as an internal standard to normalize the variations. The degree of conversion was calculated using the following Equation:

$$
\text { Conversion }(\%)=\left[1-\left(A_{3011} / A_{2928}\right)_{\text {after reaction }} /\left(A_{3011} / A_{2928}\right)_{\text {before reaction }}\right] \times 100
$$

where $A_{3011}$ and $A_{2928}$ are the absorbance values of the 3011 and $2928 \mathrm{~cm}^{-1}$ bands, respectively.

\subsection{Microencapsulation of Linseed Oil}

Water $(200 \mathrm{~mL})$ and a $2.5 \mathrm{wt} \%$ aqueous solution of EMA $(50 \mathrm{~mL})$ were added to a $600 \mathrm{~mL}$ beaker. The beaker was placed in a water bath. Urea (5.030 g), ammonium chloride (0.500 g) and resorcinol $(0.500 \mathrm{~g})$ were added under agitation at $300 \mathrm{rpm}$. The $\mathrm{pH}$ of the resulting mixture was adjusted to 3.5 using a $10 \mathrm{wt} \% \mathrm{NaOH}$ solution. The mixture was stirred at $2000 \mathrm{rpm}$ with a mechanical stirrer and $2 \mathrm{~mL}$ of 1-octanol was added. Then, $80 \mathrm{~mL}$ of linseed oil was added and the mixture was stirred at $2000 \mathrm{rpm}$ for $20 \mathrm{~min}$ to form a stable emulsion. After adding a $37 \mathrm{wt} \%$ formaldehyde solution $(14.560 \mathrm{~g})$, the temperature of the mixture was increased to $60{ }^{\circ} \mathrm{C}$, which was maintained for $5 \mathrm{~h}$. The resulting suspension was cooled to room temperature and microcapsules were filtered using vacuum filtration. The microcapsules were washed with water and ethyl alcohol (yield =95\%). The yield of the microencapsulation is defined by the ratio of the mass of recovered microcapsules to the total mass of the core and shell constituents.

\subsection{Measurement of Microcapsule Core/Shell Ratio}

After weighing, the linseed-oil-containing microcapsules were crushed by pressing in a $5 \mathrm{~mL}$ vial and washed with ethanol twice. The ruptured shell material was dried under ambient condition and weighed. Core weight was calculated by subtracting shell weight from the microcapsule weight. The core/shell ratio was determined from the core and shell weights.

\subsection{Preparation of the Coating Samples}

The preparation procedure is shown in Figure S2 in Supplementary Materials. The linseed-oil-containing microcapsules were added into the commercial undercoating formulation with a capsule:formulation mass ratio of 5:95, 10:90, 20:80, or 30:70. Each mixture was blended by vortexing for $5 \mathrm{~min}$. The resulting formulations were applied to the surface of mortar specimens (see above) or silicon wafers and then dried for $3 \mathrm{~h}$ at room temperature. The resulting coatings were covered with a top-coating formulation, followed by drying for $1 \mathrm{~h}$. The top-coating formulation was applied again and the resultant coatings were dried under ambient conditions for $48 \mathrm{~h}$. Control coating samples were prepared in a similar fashion without microcapsules. The thicknesses of the undercoating and top-coating layers were measured to be about 50 and $200 \mu \mathrm{m}$, respectively. The coated mortar samples were used for adhesion strength measurement, water sorptivity test, saline solution sorptivity test and accelerated carbonation test.

\subsection{Adhesion Strength Measurement}

Pull-off testing was conducted to investigate the effects of microcapsule loading on coating adhesion according to the KSF 4936 standard method. The self-healing and control coatings were 
applied to one square side of $70 \times 70 \times 20 \mathrm{~mm}^{3}$ prism mortars. A square side of a $40 \times 40 \times 10 \mathrm{~mm}^{3}$ steel zig was attached to each coating. The coating was scored through to the substrate around the steel zig with a cutter before running the test. After keeping each specimen at room temperature, it was placed into an adhesion-tester. The load to the zig was increased and the force attained at failure was recorded. In each case, three measured adhesion strength values were averaged. The adhesion strength was calculated using the following equation.

$$
\text { Adhesion Strength }\left(\mathrm{N} \cdot \mathrm{mm}^{-2}\right)=\text { Maximum force applied }(\mathrm{N}) / 1600 \mathrm{~mm}^{2}
$$

\subsection{Water Sorptivity Test}

The test procedure is shown in Figure S3 in Supplementary Materials. The self-healing and control coatings were applied to one rectangular side of $40 \times 40 \times 130 \mathrm{~mm}^{3}$ prism mortars. Scratches were applied to the self-healing and control coatings with two types of cutters. It was confirmed that each cut was deep enough to reach the surface of the mortar. The scratch width was measured by microscopy to be approximately 30 or $90 \mu \mathrm{m}$. For the other specimens, microcracks were generated in the coated surface of the mortar specimens with a UTM by pressing the center part of back side of the coated side to a given extent at a rate of loading of $500 \mathrm{~N} \mathrm{~min}^{-1}$ (Figure 44 in Supplementary Materials). Scratch or crack width was measured at 10 points along the length of each scratch or crack and the values were averaged. After generating scratch or crack, four side surfaces adjacent to the coated side were covered with epoxy resin to prevent water permeation through the adjacent surfaces. After storing the specimens for $48 \mathrm{~h}$ at room temperature $\left(23-27^{\circ} \mathrm{C}\right)$ to induce self-healing, the scratched surface was continuously brought into contact with water at room temperature $\left(23-27^{\circ} \mathrm{C}\right)$. After $48 \mathrm{~h}$, the increase in mass due to water absorption was determined. For each kind of sample, three specimens were tested and an average of the measured values was calculated.

\subsection{Saline Solution Sorptivity Test}

The procedure for saline solution sorptivity test is shown in Figure S5 (Supplementary Materials). The self-healing coatings and control coatings were applied to one rectangular side of $40 \times 40 \times 130 \mathrm{~mm}^{3}$ prism mortars. Four side surfaces adjacent to the coated side were covered with epoxy resin. The coated mortar specimens were stored at $-20{ }^{\circ} \mathrm{C}$ for $24 \mathrm{~h}$ in the low-temperature chamber. Immediately after opening the chamber door, scratches were applied to the self-healing and control coatings with a 30- $\mu \mathrm{m}$-thick cutter inside the chamber. It was confirmed that each cut was deep enough to reach the surface of the mortar. After the scratched coatings were weighed, they were left at $-20^{\circ} \mathrm{C}$ for $48 \mathrm{~h}$ in the chamber. The scratching and weighing took only about $30 \mathrm{~s}$ and the temperature of the samples was maintained at $-20{ }^{\circ} \mathrm{C}$. The scratched surface was immediately immersed in a saline solution $(25 \mathrm{wt} \% \mathrm{NaCl}$ aqueous solution) that was being maintained at $-20{ }^{\circ} \mathrm{C}$ in the chamber. A $25 \mathrm{wt} \%$ saline solution was used instead of water for the sorptivity test because the saline solution does not freeze at $-20^{\circ} \mathrm{C}$. After $48 \mathrm{~h}$, the increase in the mass of mortar due to absorbed saline solution was determined by weighing each specimen. For each kind of sample, three replicates were tested and an average of the measured mass was calculated.

\subsection{Determination of Healing Efficiency}

Healing efficiency was calculated using the following equation,

$$
\text { Healing efficiency }(\%)=\left(1-U_{\text {self-healing }} / U_{\text {control }}\right) \times 100
$$

where $U_{\text {self-healing }}$ is water or saline solution uptake of self-healing specimens and $U_{\text {control }}$ is water or saline solution uptake of control specimens. The healing efficiency is based on a general self-healing efficiency definition described in a review article [5]. 


\subsection{Accelerated Carbonation Test}

The self-healing or control coating was applied to one side of $100 \times 100 \times 100 \mathrm{~mm}^{3}$ cubic mortar (Figure S2c in Supplementary Materials). The other five sides except the coated side were covered with epoxy resin. Scratches were applied to the self-healing and control coatings with a 30- $\mu$ m-thick cutter. It was confirmed that each cut was deep enough to reach the surface of the mortar. The carbonation test was conducted using an acceleration tester at $20{ }^{\circ} \mathrm{C}$ and $65 \%$ relative humidity for 28 days. The concentration of carbon dioxide was 5\%. The depth of carbonation was measured by use of phenolphthalein. For each kind of sample, two specimens were tested and an average of the measured values was calculated.

\section{Results and Discussion}

\subsection{Linseed Oil Healing Agent}

It is well known that linseed oil undergoes an oxidative drying reaction upon exposure to air. Linseed oil was applied to a petri dish and exposed to air to induce the drying reaction. The reaction of linseed oil at room temperature $\left(23-27^{\circ} \mathrm{C}\right)$ or at $-20^{\circ} \mathrm{C}$ was investigated by FT-IR spectroscopy. As shown in Figure 1a, the absorbance due to the ethylenic C-H stretch at $3011 \mathrm{~cm}^{-1}$ was reduced after reacting for 2 days at room temperature compared to the original spectrum prior to reaction. This indicates oxidative drying of the linseed oil $[6,10]$. The reaction of linseed oil at $-20{ }^{\circ} \mathrm{C}$ was also studied to investigate its applicability to low-temperature self-healing. As shown in Figure 1a, the absorbance of the $3011 \mathrm{~cm}^{-1}$ band decreased, indicating that the drying reaction proceeded even at $-20^{\circ} \mathrm{C}$. On the other hand, a healing agent for low-temperature self-healing must have sufficient release property at low temperature because it needs to flow out of the broken capsules and fill the damaged region. Linseed oil has a melting point of $-24{ }^{\circ} \mathrm{C}$ and showed good flowability at $-20{ }^{\circ} \mathrm{C}$. The reaction conversion of linseed oil versus elapsed time is shown in Figure $1 \mathrm{~b}$. At room temperature, the conversion reached about $88 \%$ after 2 days and increased further at a slower rate. At $-20{ }^{\circ} \mathrm{C}$, the reaction rate was lower and the conversion reached $59 \%$ after 2 days. However, the conversion at $-20{ }^{\circ} \mathrm{C}$ reached $83 \%$ after 7 days. These results suggest that linseed oil could be used as a self-healing agent in temperatures as low as $-20^{\circ} \mathrm{C}$.
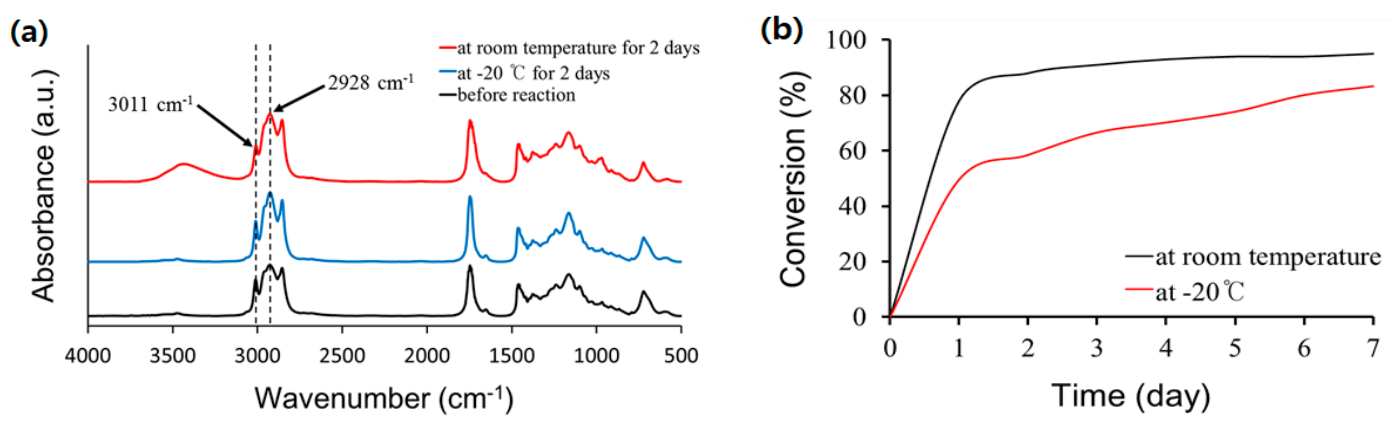

Figure 1. (a) FT-IR spectra of linseed oil before and after oxidation at room temperature or at $-20{ }^{\circ} \mathrm{C}$ for 2 days; (b) Reaction conversion of linseed oil versus time at room temperature or at $-20{ }^{\circ} \mathrm{C}$.

\subsection{Microcapsules}

Linseed oil was microencapsulated using urea-formaldehyde polymer (UF) by in situ polymerization. The morphology of the microcapsules was observed by SEM (Figure 2a). Spherical microcapsules were formed at an agitation rate of $2000 \mathrm{rpm}$ and the outer surface of the capsules was relatively rough. The size distribution of the microcapsules was investigated by optical microscopy (Figure $2 \mathrm{~b}$ ). The average diameter of the microcapsules was $53 \mu \mathrm{m}$.

The formation of linseed-oil-loaded UF microcapsules was confirmed by FT-IR spectroscopy (Figure S6 in Supplementary Material). As shown in Figure S6, the UF resin showed absorption peaks 
of $\mathrm{C}-\mathrm{N}$ stretching vibration at $1564 \mathrm{~cm}^{-1}, \mathrm{C}=\mathrm{O}$ stretching vibration at $1643 \mathrm{~cm}^{-1}$ and $\mathrm{N}-\mathrm{H}$ and $\mathrm{O}-\mathrm{H}$ stretching vibrations at $3361 \mathrm{~cm}^{-1}$. Linseed oil showed absorption peaks at $1164 \mathrm{~cm}^{-1}$ (due to ester $\mathrm{C}-\mathrm{O}$ stretching), $1747 \mathrm{~cm}^{-1}$ (due to ester $\mathrm{C}=\mathrm{O}$ stretching), $2928 \mathrm{~cm}^{-1}$ (due to $\mathrm{C}-\mathrm{H}\left(-\mathrm{CH}_{2}-\right)$ stretching) and $3011 \mathrm{~cm}^{-1}$ (due to $\mathrm{C}-\mathrm{H}(=\mathrm{CH}-)$ stretching). The main absorption peaks of the UF resin and linseed oil were observed in the spectrum of the microcapsules. In addition, the IR spectrum of an authentic linseed oil was practically the same as that of a substance released from the microcapsules crushed by pressing with a spatula (data not shown). These results indicate the successful formation of linseed-oil-loaded UF microcapsules.

(a)

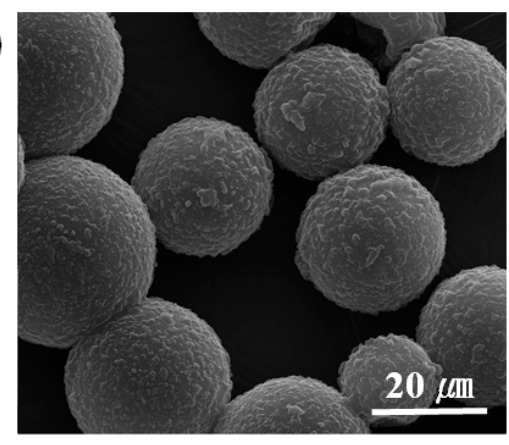

(b)

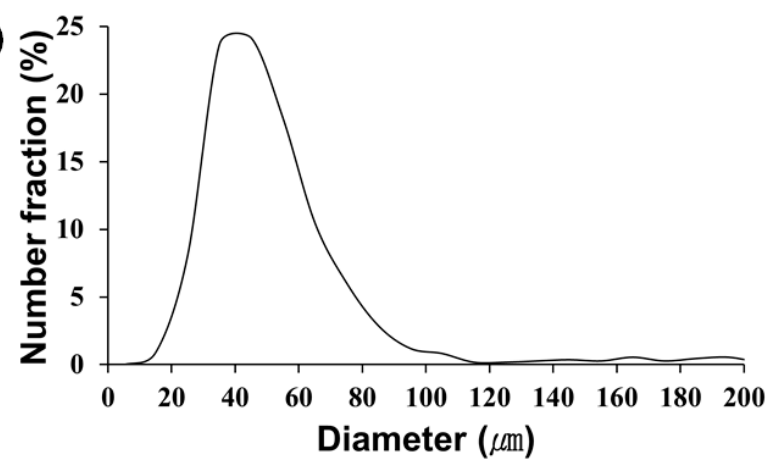

Figure 2. (a) SEM image of the linseed oil microcapsules; (b) Size distribution of the linseed oil microcapsules.

It was found that the linseed-oil-loaded microcapsules had a core:shell mass ratio of 61:39. After storage for 13 months in a temperature range of $10-25^{\circ} \mathrm{C}$, the capsule's external appearance was unchanged (Figure S7 in Supplementary Materials) and the core still flowed out of the ruptured capsules and underwent the oxidation reaction.

\subsection{Preparation and Adhesion Property of the Self-Healing Coating}

The linseed-oil-containing microcapsules were integrated into a commercially available protective coating formulation at 10, 20, or $30 \mathrm{wt} \%$ to prepare self-healing coating formulations. Each formulation was applied on mortar specimens and the resultant coating layer was covered with a top-coating layer (Figure S2a in Supplementary Materials). Control coating samples were also prepared without microcapsules (i.e., at $0 \mathrm{wt} \%$ capsule loading).

Because the added microcapsules with core-shell structure would weaken the bonding between the undercoating layer and the mortar surface, the adhesion strength was investigated by pull-off testing for the control and self-healing coatings. As shown in Figure 3, the self-healing coating with $10 \mathrm{wt} \%$ capsule loading showed a strength similar to that of the control coating. The self-healing coatings with 20 or $30 \mathrm{wt} \%$ capsule loading showed somewhat lower strength. This indicates that the adhesion property of the coating decreased with incorporation of $20 \mathrm{wt} \%$ or more microcapsules. However, the self-healing coatings showed adhesion strength values higher than $1.3 \mathrm{~N} \mathrm{~mm}^{-2}$, which is sufficient to be used as protective coating for cementitious materials. 


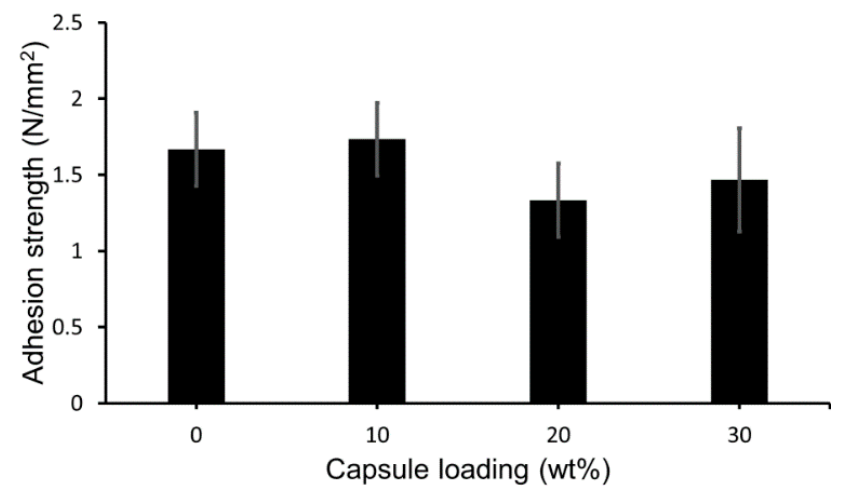

Figure 3. Adhesion strength of the control and self-healing coatings with 0 (control), 10, 20 and $30 \mathrm{wt}$ $\%$ capsule loading.

\subsection{SEM Study of Self-Healing}

The coating formulation with $20 \mathrm{wt} \%$ capsule loading was applied on one side of a silicon wafer and the resultant coating layer was covered with a top-coating layer. The self-healing coating was scratched with a 30- $\mu \mathrm{m}$-thick cutter and left for $48 \mathrm{~h}$ at room temperature to induce self-healing. A scratched control coating was also prepared in a similar fashion without microcapsules. From the SEM image of the scratched area in the linseed-oil-based self-healing coating, it was confirmed that the healing agent filled the scratched region, indicating effective healing of the scratch (Figure $4 \mathrm{~b}$ ), while the scratch remained unfilled in the control coating (Figure 4a).
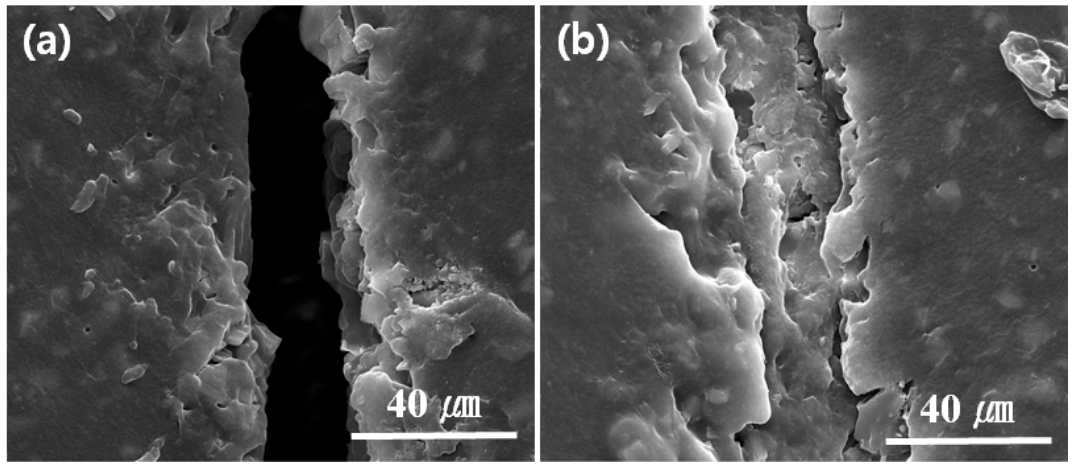

Figure 4. SEM images of scratched (a) control and (b) self-healing coatings.

\subsection{Water Sorptivity Test}

To evaluate preliminarily the applicability of the linseed oil microcapsule-based self-healing coating system to cementitious composite materials, a water sorptivity test was conducted using coated mortar specimens (Figure 5) [24,25]. Each specimen was prepared by application of the control or self-healing coating formulation to one rectangular side of a square column mortar and by scratching the coated surface of the mortar with two types of cutters. The scratch width was measured by optical microscopy to be approximately 30 or $90 \mu \mathrm{m}$. It was confirmed that each cut was deep enough to reach the mortar surface. The scratched self-healing coatings were allowed to heal for $48 \mathrm{~h}$ at room temperature and then the water sorptivity test was conducted at room temperature. 
(a)

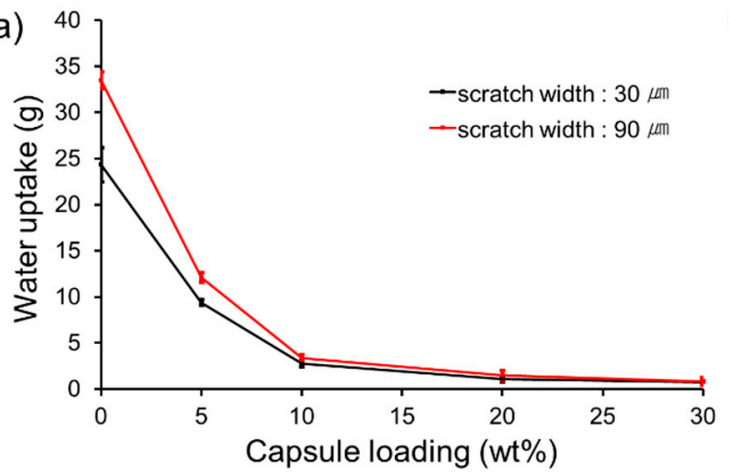

(b)

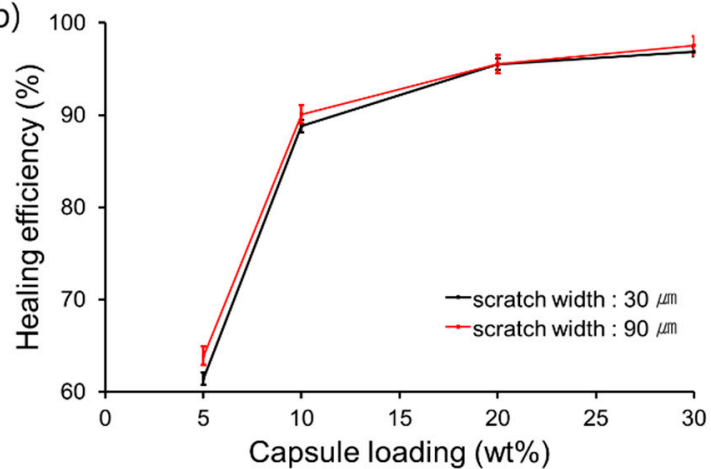

Figure 5. (a) Water uptake versus capsule loading of the coated mortar specimens. A scratch was applied on the surface of each coating at a width of 30 or $90 \mu \mathrm{m}$; (b) Healing efficiency versus capsule loading of the self-healing coating calculated using Equation (2) and the data shown in (a).

Figure 5a shows the amount of water uptake of the scratched control and self-healing coating specimens according to capsule loading. The water uptake amount drastically decreased with increasing capsule loading for the specimens with 0 (control) and $5 \mathrm{wt} \%$ capsule loadings and the specimens with a scratch width of $90 \mu \mathrm{m}$ showed greater water uptake than those with a 30- $\mu \mathrm{m}$-wide scratch. The specimens with capsule loadings of $10 \mathrm{wt} \%$ or more showed similar water uptake values regardless of scratch width. Figure $5 \mathrm{~b}$ shows the healing efficiency of the self-healing coatings, which was estimated using Equation (2) and the data of Figure 5a. For both scratch widths, a healing efficiency of about $90 \%$ was achieved using the specimens with $10 \mathrm{wt} \%$ capsule loading and healing efficiencies of $96 \%$ and $97 \%$ were accomplished with the specimens with 20 and $30 \mathrm{wt} \%$ capsule loadings, respectively. The results suggest that successful self-healing of $90-\mu \mathrm{m}$-wide scratch was accomplished in the self-healing protective coating system with capsule loadings of $20 \mathrm{wt} \%$ or more, leading to effective prevention of water permeation.

In addition to scratches, protective coatings for cementitious materials can often be damaged by microcracking, so the self-healing of microcracks also needs to be studied. Microcracks can occur in the coating itself and microcracks occurring in the cementitious materials may cause microcracking of the protective coating. In this study, microcracks were generated in both the mortar and the protective coating with a UTM by pressing the center part of the side opposite the coated side. The crack width was controlled by varying the pressing force. The cracked coating specimens were subjected to the water sorptivity test. The water uptake versus crack width is plotted in Figure 6. As expected, water uptake increased with increasing crack width in both self-healing and control coatings. The specimens with 20 or $30 \mathrm{wt} \%$ capsule loading showed similar water uptake and they had lower water uptake values than the specimens with $10 \mathrm{wt} \%$ capsule loading. For the specimens with $20 \mathrm{or} 30 \mathrm{wt} \%$ capsule loading, the water uptake remained below about $10 \mathrm{~g}$ until around $150 \mu \mathrm{m}$ crack width; above $150 \mu \mathrm{m}$ width, water uptake greatly increased with increasing crack width. The healing efficiency of the self-healing coatings with 20 or $30 \mathrm{wt} \%$ capsule loading was roughly calculated to be 90,85 and $70 \%$ when the crack widths were around 50,100 and $150 \mu \mathrm{m}$, respectively. It was found that the healing efficiencies of crack healing were somewhat lower than those of scratch healing. This may be attributed to volume of crack larger than that of scratch. 


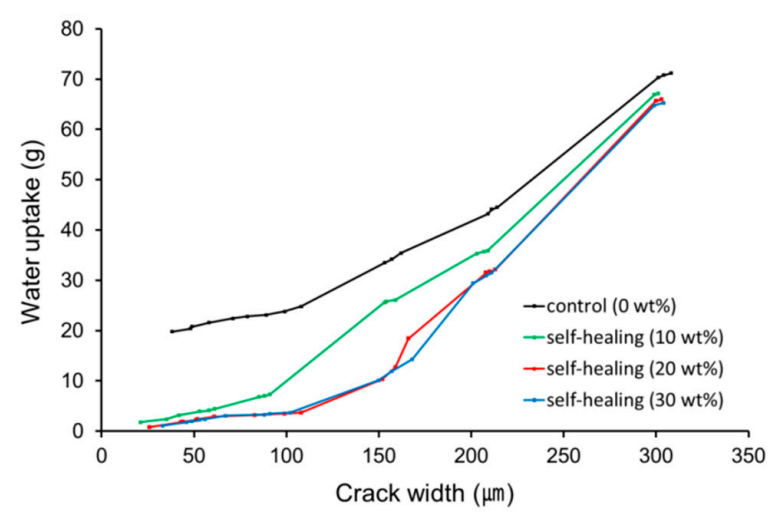

Figure 6. Water uptake versus crack width of the control and self-healing coatings with capsule loadings of 10,20 and $30 \mathrm{wt} \%$.

To investigate the stability of the self-healing coating, water sorptivity tests were conducted for the self-healing coating samples that were prepared seven months ago and have been stored under laboratory conditions. The external appearance and self-healing performance of the coatings remained almost unchanged: the specimens with a capsule loading of $20 \mathrm{wt} \%$ with a scratch width of $30 \mu \mathrm{m}$ showed a healing efficiency of $95 \%$.

\subsection{Low-Temperature Self-Healing-Saline Solution Sorptivity Test}

The applicability of the linseed-oil-based self-healing coating system to cementitious material at a low temperature $\left(-20^{\circ} \mathrm{C}\right)$ was evaluated (Figure 7$)$. A $25 \mathrm{wt} \%$ saline solution was used instead of water for the sorptivity test because the saline solution does not freeze at $-20^{\circ} \mathrm{C}$. Each specimen was prepared by applying the control or self-healing coating formulation to one rectangular side of the column mortars. Control and self-healing coatings were stored, scratched and then stored again inside the low-temperature chamber at $-20^{\circ} \mathrm{C}$. A scratch was applied in each coating and optical microscopy showed that the scratch width was about $30 \mu \mathrm{m}$. The scratched surfaces of the control and self-healing coatings were immersed in a saline solution at $-20^{\circ} \mathrm{C}$ for $48 \mathrm{~h}$. In Figure $7 \mathrm{a}$, the amount of saline solution uptake of the coating specimens is compared to the water uptake of the specimens at room temperature. The uptake values at the capsule loadings were similar and the healing efficiency showed the same tendency (Figure $7 \mathrm{~b}$ ). These results indicate that successful low-temperature self-healing of damage was accomplished in our self-healing coating system.
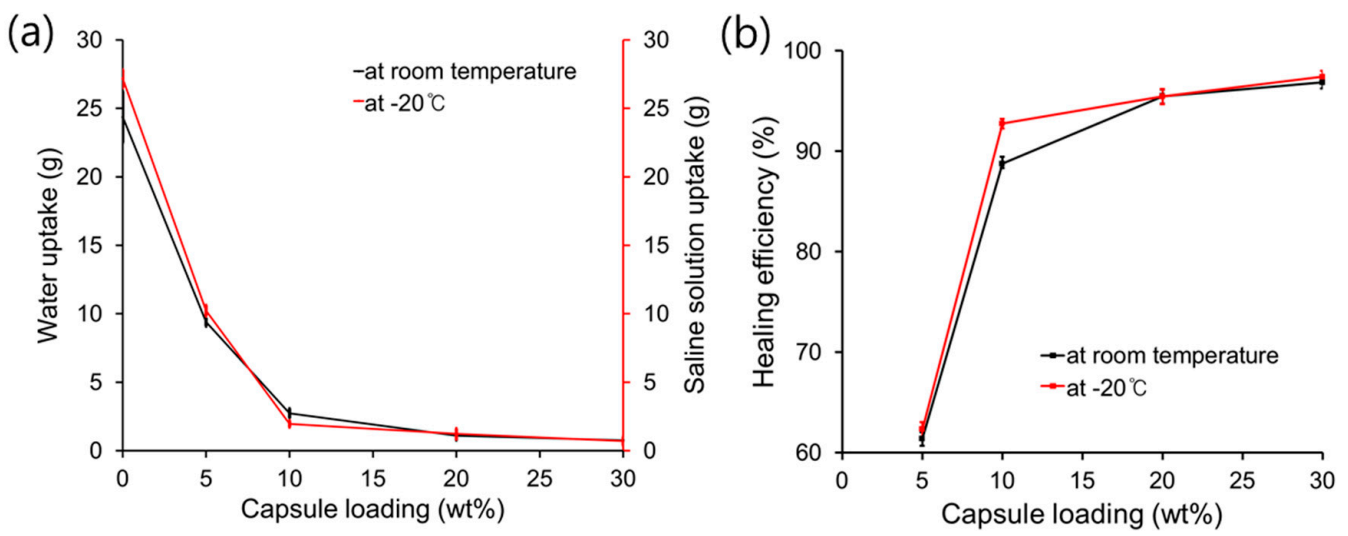

Figure 7. (a) Water or saline solution uptake versus capsule loading for coated mortar specimens; (b) Healing efficiency versus capsule loading of the self-healing coatings calculated using Equation (2) and data from Figure 7a. 


\subsection{Carbonation Test of the Self-Healing Coatings}

A protective coating formulation with $20 \mathrm{wt} \%$ capsules was applied on mortar specimens to prepare self-healing coatings (Figure S2c in Supplementary Materials). Control coating samples were prepared without microcapsules. The accelerated carbonation test was conducted for the scratched control and self-healing coatings. The carbonation of mortar with self-healing coating was measured to be $0.0 \mathrm{~mm}$ in depth. In contrast, the carbonation depth of mortar with damaged control coating was measured to be about $2.4 \mathrm{~mm}$. This indicates that the self-healing coating healed the damage, resulting in effective protection of the substrate mortar from carbonation.

\section{Conclusions}

Linseed oil reacted upon exposure to air, generating a soft film. The reaction conversion after $48 \mathrm{~h}$ reached $88 \%$ and $59 \%$ when it was reacted at room temperature and at $-20{ }^{\circ} \mathrm{C}$, respectively. Linseed-oil-loaded microcapsules with an average diameter of $53 \mu \mathrm{m}$ were prepared using UF polymer as the shell wall material. The microcapsules were integrated into a commercially available protective coating formulation to prepare self-healing coating formulations with different capsule loadings. The coating formulations were applied on mortar specimens to prepare self-healing coatings. The adhesion property of the coating somewhat decreased with incorporation of 20 or $30 \mathrm{wt} \%$ microcapsules but the self-healing coatings showed adhesion strength values higher than $1.3 \mathrm{~N} \mathrm{~mm}^{-2}$. The self-healing of scratch or crack damage in the coating was demonstrated by SEM observations, a water sorptivity test and an accelerated carbonation test. Using coating specimens with $20 \mathrm{wt} \%$ capsule loading, $90-100-\mu \mathrm{m}$-wide scratch or crack could be self-healed at about $90 \%$ or higher healing efficiency. Low-temperature self-healing was also demonstrated by a saline sorptivity test at $-20^{\circ} \mathrm{C}$. The linseed-oil-based microcapsule-type self-healing coating system is a promising candidate as a protective coating for cementitious materials.

Supplementary Materials: The following are available online at http:/ /www.mdpi.com/2079-6412/8/11/404/s1, Figure S1: Chemical structure of linseed oil; Figure S2: Procedures of coated mortar specimens for (a) adhesion strength measurement, (b) water sorptivity test and (c) accelerated carbonation test; Figure S3: Procedure for water sorptivity test; Figure S4: Generation of a crack on coated side of a mortar specimen by UTM; Figure S5: Procedure for saline solution sorptivity test; Figure S6: FT-IR spectra of linseed oil, UF and microcapsules; Figure S7: Images of linseed oil-contained microcapsules.

Author Contributions: Conceptualization, C.-M.C. and D.-M.K.; Methodology, D.-M.K.; Formal Analysis, I.-H.S. and J.-Y.C.; Investigation, D.-M.K., S.-W.J. and K.-N.N.; Writing-Original Draft Preparation, C.-M.C. and D.-M.K.; Writing-Review \& Editing, C.-M.C.; Supervision, C.-M.C.

Funding: This research was supported by a grant (18SCIP-B103706-04) from the Construction Technology Research Program funded by the Ministry of Land, Infrastructure and Transport of the Korean government.

Acknowledgments: We thank Samjoong Construction Chemicals Co for providing us with the undercoating and top-coating formulations.

Conflicts of Interest: The authors declare no conflict of interest.

\section{References}

1. Samadzadeh, M.; Boura, S.H.; Peikan, M.; Kasiriha, S.M.; Ashrafi, A. A review on self-healing coatings based on micro/nanocapsules. Prog. Org. Coat. 2010, 68, 159-164. [CrossRef]

2. Wei, H.; Wang, Y.; Guo, J.; Shen, N.Z.; Jiang, D.; Zhang, X.; Yan, X.; Zhu, J.; Wang, Q.; Shao, L.; et al. Advanced micro/nanocapsules for self-healing smart anticorrosion coatings. J. Mater. Chem. A 2015, 3, 469-480. [CrossRef]

3. Shchukin, D.G. Container-based multifunctional self-healing polymer coatings. Polym. Chem. 2013, 4, 4871-4877. [CrossRef]

4. Hia, L.L.; Vahedi, V.; Pasbakhsh, P. Self-healing polymer composites: Prospects, challenges and applications. Polym. Rev. 2016, 56, 225-261. [CrossRef]

5. Blaiszik, B.J.; Kramer, S.L.B.; Olugebefola, S.C.; Moore, J.S.; Sottos, N.R.; White, S.R. Self-healing polymers and composites. Annu. Rev. Mater. Res. 2010, 40, 179-211. [CrossRef] 
6. Lazzari, M.; Chiantore, O. Drying and oxidative degradation of linseed oil. Polym. Degrad. Stab. 1999, 65, 303-313. [CrossRef]

7. Suryanarayana, C.; Rao, K.C.; Kumar, D. Preparation and characterization of microcapsules containing linseed oil and its use in self-healing coatings. Prog. Org. Coat. 2008, 63, 72-78. [CrossRef]

8. Jadhav, R.S.; Hundiwale, D.G.; Mahulikar, P.P. Synthesis and characterization of phenol-formaldehyde microcapsules containing linseed oil and its use in epoxy for self-healing and anticorrosive coating. J. Appl. Polym. Sci. 2011, 119, 2911-2916. [CrossRef]

9. Boura, S.H.; Peikari, M.; Ashrafi, A.; Samadzadeh, M. Self-healing ability and adhesion strength of capsule embedded coatings micro and nano sized capsules containing linseed oil. Prog. Org. Coat. 2012, 75, 292-300. [CrossRef]

10. Szabo, T.; Telegdi, J.; Nyikos, L. Linseed oil-filled microcapsules containing drier and corrosion inhibitor-Their effects on self-healing capability of paints. Prog. Org. Coat. 2015, 84, 136-142. [CrossRef]

11. Nesterova, T.; Dam-Johansen, K.; Pedersen, L.T.; Kiil, S. Microcapsule-based self-healing anticorrosive coatings: Capsule size coating formulation and exposure testing. Prog. Org. Coat. 2012, 75, 309-318. [CrossRef]

12. Behzadnasab, M.; Esfandeh, M.; Mirabedini, S.M.; Zohuriaan-Mehr, M.J.; Farnood, R.R. Preparation and characterization of linseed oil-filled urea-formaldehyde microcapsules and their effect on mechanical properties of an epoxy-based coating. Colloids Surf. A Physicochem. Eng. Asp. 2014, 457, 16-26. [CrossRef]

13. Hasanzadeh, M.; Shahidi, M.; Kazemipour, M. Application of EIS and EN techniques to investigate the self-healing ability of coatings based on microcapsules filled with linseed oil and $\mathrm{CeO}_{2}$ nanoparticles. Prog. Org. Coat. 2015, 80, 106-119. [CrossRef]

14. Lang, S.; Zhou, Q. Synthesis and characterization of poly (urea-formaldehyde) microcapsules containing linseed oil for self-healing coating development. Prog. Org. Coat. 2017, 105, 99-110. [CrossRef]

15. Behzadnasab, M.; Mirabedini, S.M.; Esfandeh, M.; Farnood, R.R. Evaluation of corrosion performance of a self-healing epoxy-based coating containing linseed oil-filled microcapsules via electrochemical impedance spectroscopy. Prog. Org. Coat. 2017, 105, 212-224. [CrossRef]

16. Abdipour, H.; Rezaei, M.; Abbasi, F. Synthesis and characterization of high durable linseed oil-urea formaldehyde micro/nanocapsules and their self-healing behavior in epoxy coating. Prog. Org. Coat. 2018, 124, 200-212. [CrossRef]

17. Mahmoudian, M.; Nozad, E.; Kochameshki, M.G.; Enayati, M. Preparation and investigation of hybrid self-healing coatings containing linseed oil loaded nanocapsules, potassium ethyl xanthate and benzotriazole on copper surface. Prog. Org. Coat. 2018, 120, 167-178. [CrossRef]

18. Wang, H.; Zhou, Q. Evaluation and failure analysis of linseed oil encapsulated self-healing anticorrosive coating. Prog. Org. Coat. 2018, 118, 108-115. [CrossRef]

19. Ebrahiminiya, A.; Khorram, M.; Hassanajili, S.; Javidi, M. Modeling and optimization of the parameters affecting the in-situ microencapsulation process for producing epoxy-based self-healing anti-corrosion coatings. Particuology 2018, 36, 59-69. [CrossRef]

20. Zandi, M.S.; Hasanzadeh, M. The self-healing evaluation of microcapsule-based epoxy coatings applied on AA6061 Al alloy in 3.5\% NaCl solution. Anti-Corros. Methods Mater. 2017, 64, 225-232. [CrossRef]

21. Patil, D.; Rane, A.V.; Kanny, K.; Abitha, V.K.; Sabnis, A. Urea-phenol-formaldehyde microcapsules containing linseed oil for self-healing anticorrosive coating applications. Adv. Mater. Lett. 2016, 7, 897-902. [CrossRef]

22. Thanawala, K.; Khanna, A.S.; Singh Raman, R.K. Development of self-healing coatings using encapsulated linseed oil and tung oil as healing agents. In Proceedings of the CORROSION 2016, Vancouver, BC, Canada, 6-10 March 2016.

23. Wu, M.; Johannesson, B.; Geiker, M. A review: Self-healing in cementitious materials and engineered cementitious composite as a self-healing material. Constr. Build. Mater. 2012, 28, 571-583. [CrossRef] 
24. Song, Y.-K.; Jo, Y.-H.; Cho, S.-Y.; Yu, H.-C.; Ryu, B.-C.; Lee, S.-I.; Chung, C.-M. Sunlight-induced self-healing of a microcapsule-type protective coating. ACS Appl. Mater. Interfaces 2013, 5, 1378-1384. [CrossRef] [PubMed]

25. Kim, D.-M.; Yu, H.-C.; Yang, H.-I.; Cho, Y.-J.; Lee, K.-M.; Chung, C.-M. Microcapsule-type self-healing protective coating for cementitious composites with secondary crack preventing ability. Materials 2017, 10, 114. [CrossRef] [PubMed]

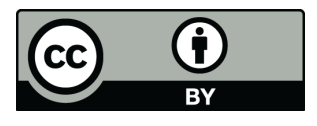

(C) 2018 by the authors. Licensee MDPI, Basel, Switzerland. This article is an open access article distributed under the terms and conditions of the Creative Commons Attribution (CC BY) license (http:/ / creativecommons.org/licenses/by/4.0/). 